\title{
RUMUS MATEMATIKA SEKOLAH DASAR BERBASIS ANDROID MENGGUNAKAN ADT (ANDROID DEVELOPER TOOLS)
}

\author{
Oleh : \\ Januardi Rosyidi Lubis ${ }^{1)}$, Rahmad Fauzi ${ }^{2}$, Muhammad Fauzan3', Lia Purnama Sari ${ }^{4}$ \\ ${ }^{1}$ Institut Pendidikan Tapanuli Selatan \\ Email : januardirl@gmail.com \\ ${ }^{2}$ Institut Pendidikan Tapanuli Selatan \\ Email : udauzi@gmail.com \\ ${ }^{3}$ Politeknik Perdana Mandiri \\ Email : Prosonal.fauzan@gmail.com, \\ ${ }^{4}$ Institut Pendidikan Tapanuli Selatan \\ Email : liasari2808@gmail.com
}

\begin{abstract}
Abstrak
Rumus matematika adalah ringkasan atau ketetapan ilmu matematika yang dilambangkan dalam bentuk simbol, huruf atau angka dan dinyatakan dalam bentuk ringkas. Penelitian ini bertujuan untuk mendeskripsikan rumus matematika dalam bentuk smarthpone dengan sistem android 2.2 (Froyo) agar lebih edukatif dan interaktif. Rumus-rumus matematika sangat membantu para siswa dalam proses mempelajari matematika. Untuk mempermudah para siswa dalam menggunakan rumus-rumus matematika dikembangkan sebuah aplikasi kumpulan rumus matematika berbasis android. Perancangan sistem ini memuat materi rumus matematika dan latihan soal agar siswa dapat mengerjakan soal latihan. Aplikasi rumus matematika ini ditujukan pada siswa sekolah dasar (SD) untuk membantu siswa dalam menguasai rumus matematika. Adanya aplikasi kumpulan rumus matematika berbasis android ini dapat memudahkan para siswa dalam mencari rumus-rumus matematika dengan cepat dan menyajikan penggunaan rumus-rumus matematika dalam bentuk contoh soal lebih efisien.
\end{abstract}

Kata kunci : Rumus Matematika, Sekolah Dasar, ADT (Android Developer Tools)

\section{PENDAHULUAN}

Pelajaran matematika dianggap sebagai pelajaran yang sulit karena banyak siswa yang mengeluh dan tidak menyukai pelajaran matematika. Salah satu faktornya yaitu susahnya siswa memahami rumus matematika padahal sebenarnya matematika bisa menjadi mudah dan menyenangkan jika di jelaskan dengan cara yang mudah dimengerti dan dipahami oleh siswa.

Dalam matematika sering dikaitkan dengan rumus, siswa merasa jika tidak bisa menguasai rumus tersebut maka mereka menganggap matematika sebagai pelajaran yang membosankan. Maka dari itu perlu dibuat sebuah media mengefisiensikan materi yang banyak menjadi lebih ringkas dan manarik untuk disajikan kepada siswa dan siswi sekolah dasar. Pembuatan aplikasi rumus matematika dibuat menggunakan software ADT (Android Developer Tools) sehingga dengan adanya aplikasi ini diharapkan mampu membuat siswa ingin belajar matematika. Peneliti sebelumnya juga membahas mengenai Perancangan Aplikasi Pembelajaran Rumus Matematika Matriks dan Trigonometri Berbasis Android (android development kit) dan Java JDK (Java Development Kit).

Kemudian pada penelitian lain juga disebutkan bahwa Penelitian aplikasi yang dilakukan oleh Rochmansyah (2012) tentang pengambangan aplikasi pembelajaran menulis bahasa arab. Yaitu pengajaran menulis huruf arab bertujuan agar siswa dapat mengenali huruf-huruf arab, dapat membedakan dengan huruf lain, dan dapat menuliskan dengan baik dan benar. Hasil aplikasi adalah materi tentang 28 huruf arab sesuai aturan, baik menulis huruf tunggal, huruf dengan harokat, maupun huruf sambung yang akan memudahkan bagi penggguna untuk mengenal dan mempelajari bahasa arab.

Setelah peneliti terdahulu melakukan penelitian pada materi matematika trigonometri maupun penulisan huruf arab. Maka peneliti perlu membuat aplikasi android dengan materi rumus matematika sekolah dasar dalam membantu siswa dan siswi sekolah dasar memahami materi matematika tingkat sekolah dasar tersebut.

\section{METODE PENELITIAN}

1. Analisis Sistem

Analisis sistem merupakan pemaparan tentang program aplikasi yang dilakukan untuk memperoleh gambaran yang jelas dan mengenai kelebihan dan kekurangan sistem yang akan dirancang. Untuk memperoleh suatu kesimpulan dari hasil pengumpulan data maka dilakukan analisis terhadap semua data yang terkumpul. Analisis data tersebut melalui proses berikut :

a. Pengumpulan data dari berbagai sumber seperti buku, artikel. 
b. Data yang dikumpulkan akan dikelompokkan dan dipilih yang mana sesuai untuk digunakan. Program ini dapat menjadi sebuah aplikasi yang mempermudah kerja manusia.

\section{Analisis Kebutuhan Non Fungsional}

Analisis non fungsional adalah sebuah tahap dimana seseorang pembangun perangkat lunak menganalisis sumber daya yang akan digunakan oleh perangkat lunak yang dibangun, sehingga dapat ditentukan kompatibilitas aplikasi yang dibangun terhadap sumber daya yang ada. Adapun kebutuhannya antara lain sebagai berikut :

\section{a. Pengertian android}

Menurut (Rahadi, 2014) Android adalah sistem operasi berbasis Linux yang dirancang untuk perangkat seluler layar sentuh seperti telepon pintar dan komputer tablet. Antarmuka pengguna Android didasarkan pada manipulasi langsung, menggunakan masukan sentuh yang serupa dengan tindakan di dunia nyata, seperti menggesek, mengetuk, mencubit, dan membalikkan cubitan untuk memanipulasi obyek di layar. Android adalah sistem operasi dengan sumber terbuka, dan Google merilis kodenya di bawah Lisensi Apache. Kode dengan sumber terbuka dan lisensi perizinan pada Android memungkinkan perangkat lunak untuk dimodifikasi secara bebas dan didistribusikan oleh para pembuat perangkat, operator nirkabel, dan pengembang aplikasi. Selain itu, Android memiliki sejumlah besar komunitas pengembang aplikasi (apps) yang memperluas fungsionalitas perangkat, umumnya ditulis dalam versi kustomisasi bahasa pemrograman Java.

b. Pengertian ADT (Android Developer Tools)

Android Development Tools (ADT) adalah plugin untuk eclipse yang didesain untuk pengembangan aplikasi android. ADT memungkinkan eclipse untuk digunakan dalam membuat aplikasi android baru, membuat user interface, menambahkan komponen berdasarkan framework API android, debug aplikasi, dan pemaketan aplikasi android. ADT memperluas kemampuan eclipse agar cepat membuat proyek android baru, membuat aplikasi UI, menambah paket berdasarkan kerangka android API, debug aplikasi menggunakan SDK android.

Pengembangan aplikasi android di eclipse dengan ADT sangat dianjurkan dan merupakan cara tercepat untuk memulai. Dengan segala fasilitas tool integrasi, editor custom $X M L$, dan panel debug, ADT memberikan dalam bantuan yang luar biasa dalam mengembangkan aplikasi android.

\section{c. Use Case}

Menurut Munawar yang dikutip dari (Kusniyati, 2016) menyatakan bahwa use case adalah deskripsi fungsi dari sebuah sistem dari perspektif pungguna. Use case bekerja dengan cara mendeskripsikan tipikal interaksi pada antar user (pengguna) sebuah sistem dengan sistemnya sendiri melalui sebuah cerita bagaimana sebuah sistem dipakai.

Tabel 1. Simbol Use Case.

\begin{tabular}{|l|l|}
\hline Simbol & Keterangan \\
\hline & $\begin{array}{l}\text { Aktor : Mewakili peran orang, sistem } \\
\text { yang lain, atau alat ketika berkomunikasi } \\
\text { dengan use case }\end{array}$ \\
\hline & $\begin{array}{l}\text { Use case : Abstraksi dan interaksi antara } \\
\text { sistem dan aktor }\end{array}$ \\
\hline & Association : Abstraksi dari penghubung \\
& antara aktor dengan use case \\
\hline
\end{tabular}

d. Flowchart

Menurut (Iswandy, 2015) Flowchart merupakan urutan-urutan langkah kerja suatu proses yang digambarkan menggunakan simbolsimbol yang disusun secara sistematis. Simbolsimbol yang digunakan untuk menggambarkan flowchart

Tabel 2. Simbol flowchart

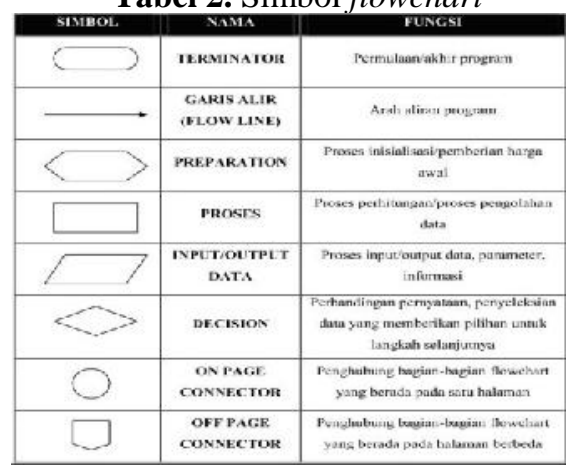

Adapun simbol flowchart diatas adalah pedoman untuk langkah kerja dalam merancang aplikasi dengan menggunakan simbol yang disusun secara sistematis. Berikut adalah langkah kerja yang dilakukan penulis dalam melaksanakan penelitian yang dapat dilihat pada gambar berikut.

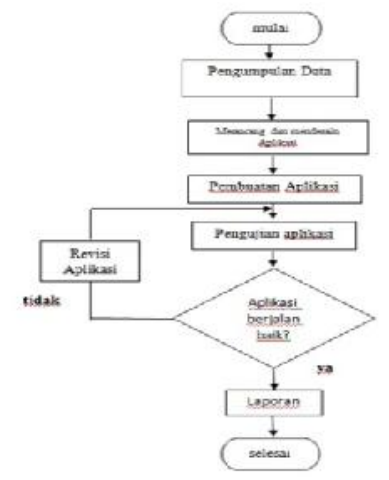

Gambar 1. Flowchart Penelitian 


\section{e. Analisis Kebutuhan Fungsional}

Analisis kebutuhan fungsional adalah suatu gambaran dari informasi yang terjadi pada sistem yang bersangkutan. Perancangan yang dilakukan yaitu perancangan program rumus matematika yang diperuntunkan kepada Guru dimana perancangan ini merupakan suatu perancangan yang telah didesain sedemikian rupa yang mampu memberikan manfaat sesuai yang diinginkan.

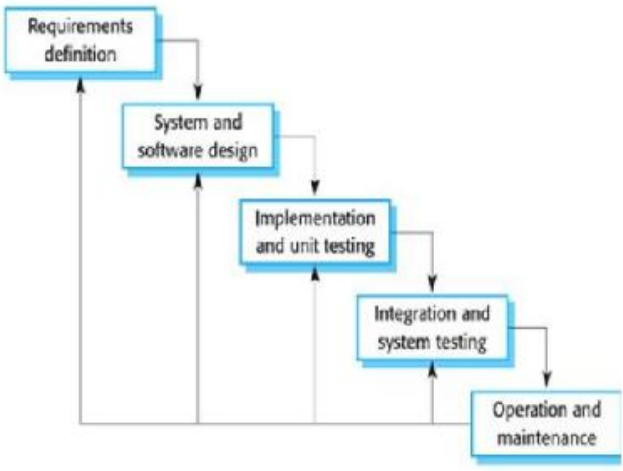

Gambar 2. Metode Waterfall

Metode penelitian yang diterapkan pada penelitian ini adalah dengan pengembangan metode waterfall. Metode waterfall merupakan model pengembangan sistem informasi yang sistematik dan sekuensial [12]. Metode Waterfall memiliki tahapan-tahapan sebagai berikut [13] :

1) Requirements analysis and definition

Layanan sistem, kendala, dan tujuan ditetapkan oleh hasil konsultasi dengan pengguna yang kemudian didefinisikan secara rinci dan berfungsi sebagai spesifikasi sistem.

2) System and software design

Tahapan perancangan sistem mengalokasikan kebutuhan-kebutuhan sistem baik perangkat keras maupun perangkat lunak dengan membentuk arsitektur sistem secara keseluruhan. Perancangan perangkat lunak melibatkan identifikasi dan penggambaran abstraksi sistem dasar perangkat lunak dan hubungannya.

3) Implementation and unit testing

Pada tahap ini, perancangan perangkat lunak direalisasikan sebagai serangkaian program atau unit program. Pengujian melibatkan verifikasi bahwa setiap unit memenuhi spesifikasinya.

4) Integration and system testing

Unit-unit individu program atau program digabung dan diuji sebagai sebuah sistem lengkap untuk memastikan apakah sesuai dengan kebutuhan perangkat lunak atau tidak. Setelah pengujian, perangkat lunak dapat dikirimkan ke customer

5) Operation and maintenance

Tahapan ini merupakan tahapan yang paling panjang. Sistem dipasang dan digunakan secara nyata. Maintenance melibatkan pembetulan kesalahan yang tidak ditemukan pada tahapan- tahapan sebelumnya, meningkatkan implementasi dari unit sistem, dan meningkatkan layanan sistem sebagai kebutuhan baru.

\section{HASIL DAN PEMBAHASAN}

Berikut fasilitas-fasilitas yang disediakan pada aplikasi yang dibuat oleh android development tool (ADK) seperti terlihat pada gambar tampilan di bawah ini :

\section{Tampilan Menu Utama Aplikasi}

Dalam menu utama ini ada 4 tombol, yaitu :

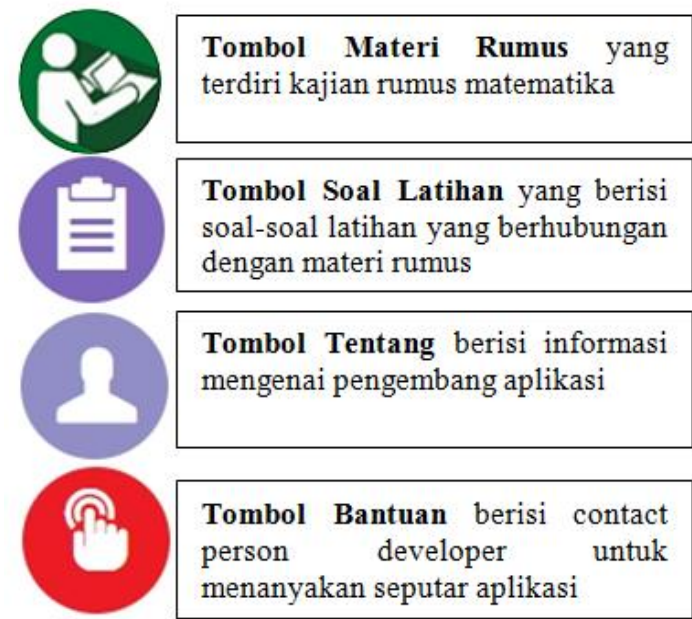

Menu Utama. Menu utama adalah bagian dari aplikasi yang muncul dengan tampilan di bawah ini

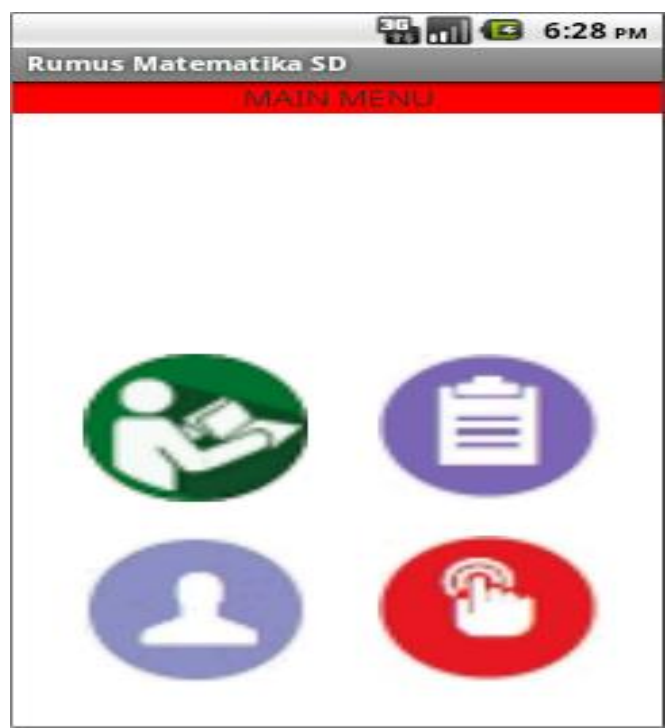

Gambar 1. Menu Utama

\section{Tampilan Daftar Rumus Matematika}

Tampilan Daftar Rumus. Daftar Rumus Ini adalah tampilan menu materi diaplikasi ini, dimana 12 (dua belas ) materi rumus diantaranya adalah operasi bilangan, bilangan pecahan, perbandingan dan skala, KPK dan FPB, Bilangan Pangkat, Jarak waktu dan Kecepatan, Bangun datar, Bangun Ruang, Memahami Kartesius, Diagram dan Statistika. 


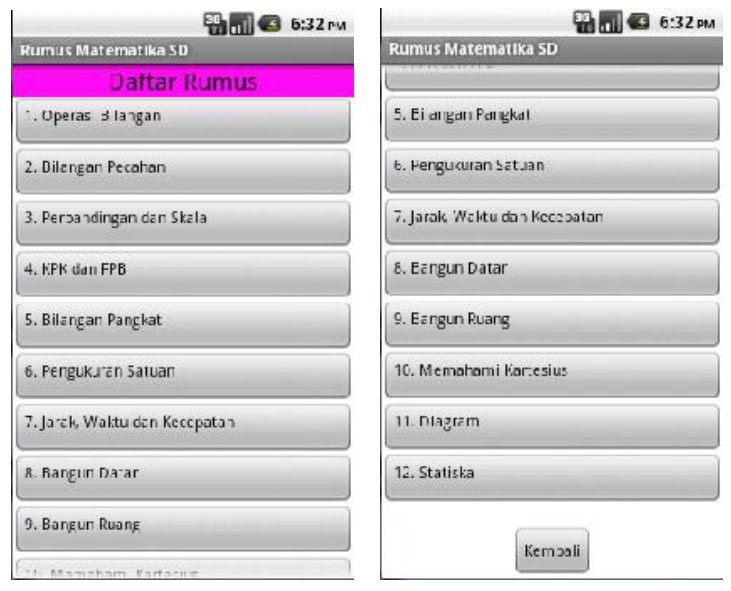

Gambar 2. Menu Daftar Materi Rumus

3. Tampilan Tombol Materi Operasi Bilangan

Pada tombol operasi bilangan terdapat rumus operasi hitung yang memuat urutan langkah kerja, contoh soal dan tips dalam menjawab soal yang serupa.

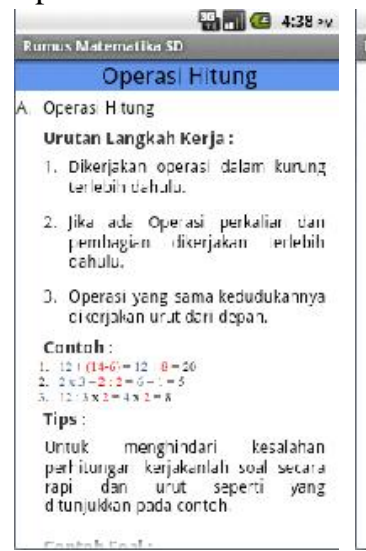

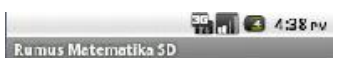

Contoh Soal:

1. D to mempunyai ocrsil sabanyak 2 kotak, Setiap kctak berisi D ta punya tersatur d dbagika? unt.uk scara amal kepada 3 ) ya:iin

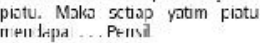
lawab:

12 ko:ak dengan setiap sotak beris s

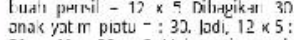
o- $60: 3 C-2$ Makd selidp alld (ing Tips:

Tantailah angka-argkta talan wal

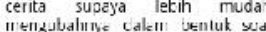
ingka.

\begin{tabular}{|c|c|c|c|}
\hline \multicolumn{4}{|c|}{ Rutras Matrmalika SD } \\
\hline \multicolumn{4}{|c|}{ 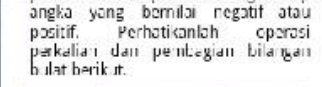 } \\
\hline 1 & & & I:I \\
\hline$\Leftrightarrow$ & & $\leftrightarrow \rightarrow$ & (t) \\
\hline (H) & & (9) & $\Leftrightarrow$ \\
\hline (1) & & $\Leftrightarrow$ & $\Leftrightarrow$ \\
\hline$\rightarrow$ & & (1) & (1) \\
\hline \multicolumn{4}{|c|}{ 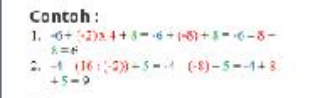 } \\
\hline \multicolumn{4}{|l|}{ Tips : } \\
\hline \multicolumn{4}{|c|}{ 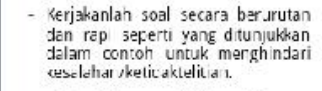 } \\
\hline \multicolumn{4}{|c|}{ 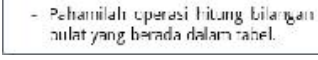 } \\
\hline \multicolumn{4}{|c|}{ 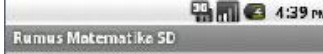 } \\
\hline \multicolumn{4}{|c|}{ 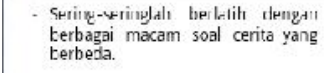 } \\
\hline \multicolumn{4}{|c|}{$\begin{array}{l}\text { B. Uperas Hi:ung Campuran Ualem } \\
\text { Zilentlln Bullat }\end{array}$} \\
\hline \multicolumn{4}{|c|}{ 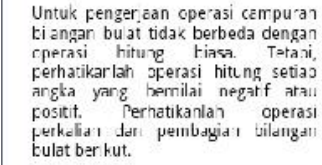 } \\
\hline I & & $1 \times n$ & I: II \\
\hline & & $\leftrightarrow$ & \\
\hline$[\rightarrow]$ & & $\Leftrightarrow$ & $\Leftrightarrow$ \\
\hline 8 & & $\Leftrightarrow$ & \\
\hline () & & $\leftrightarrow \rightarrow$ & (t) \\
\hline
\end{tabular}

Gambar 3. Tampilan Materi Operasi Bilangan

\section{Tampilan Tombol Materi Bilangan \\ Pecahan}

Pada tombol Materi bilangan pecahan terdapat rumus bilangan pecahan yang memuat urutan langkah kerja, contoh soal dan tips dalam menjawab soal yang serupa.

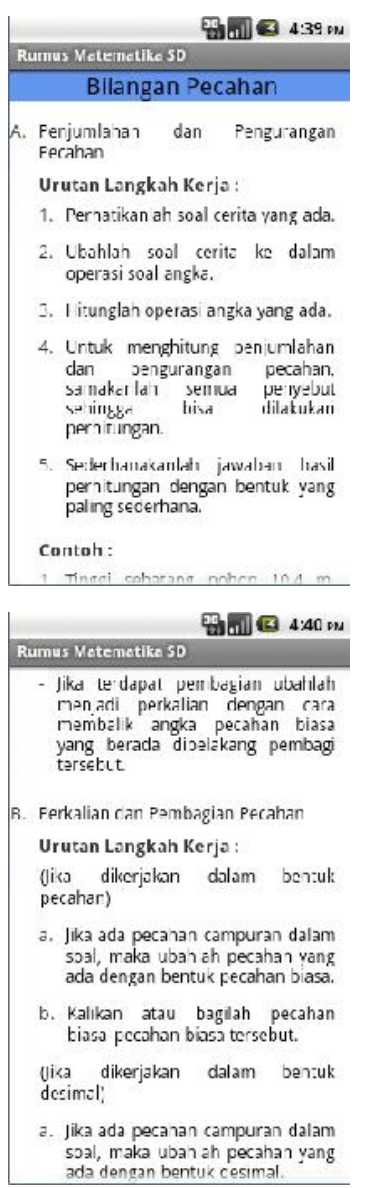

Gambar 4. Tampilan Materi Bilangan Pecahan

\section{Tampilan Tombol Materi Perbandingan dan Skala}

Pada tombol Materi Perbandingan dan Skala terdapat rumus Perbandingan dan Skala yang memuat urutan langkah kerja, contoh soal dan tips dalam menjawab soal yang serupa, sehingga memudahkan siswa dalam mengikuti langkah kerja rumus dalam menyelesaikan soal-soal.

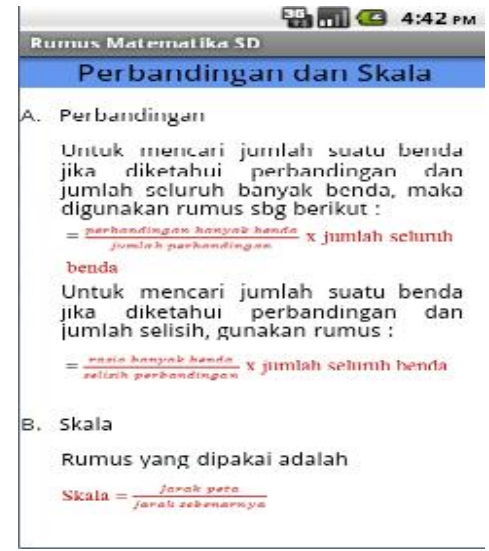

Gambar 5. Tampilan Materi Perbandingan dan Skala 


\section{Tampilan Tombol Materi KPK dan FPB}

Pada tombol Materi KPK dan FPB terdapat rumus KPK dan FPB yang memuat urutan langkah kerja, contoh soal dan tips dalam menjawab soal yang serupa, sehingga memudahkan siswa dalam mengikuti langkah kerja rumus dalam menyelesaikan soal-soal.
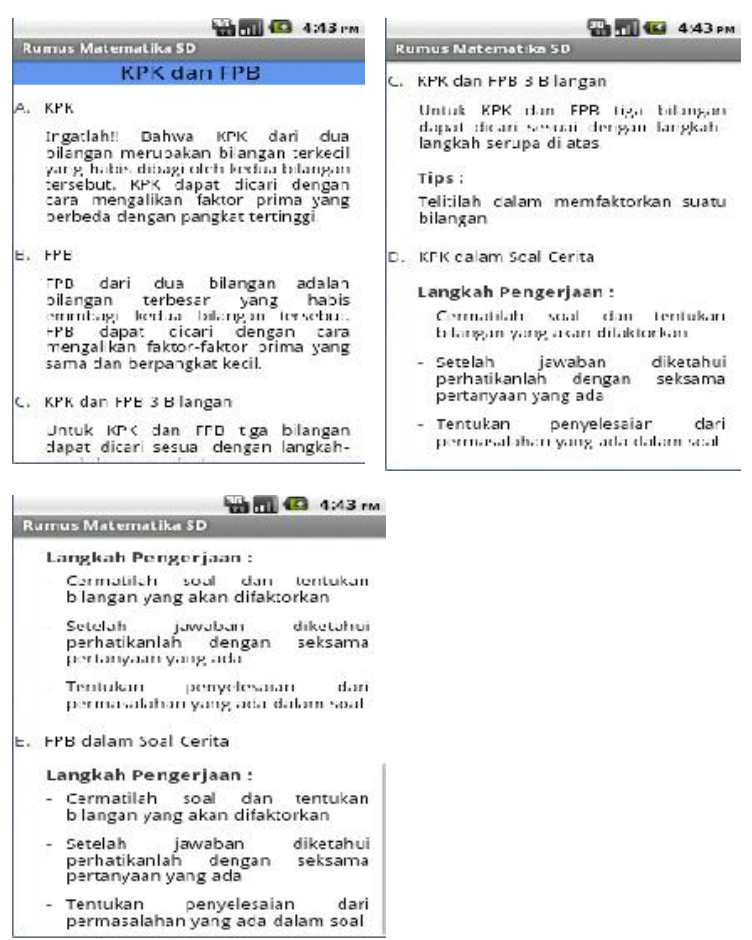

Gambar 6. Tampilan Materi KPK dan FPB

\section{Tampilan Tombol Materi Bilangan \\ Pangkat}

Pada tombol Materi Bilangan Pangkat terdapat rumus Bilangan Pangkat yang memuat urutan langkah kerja, contoh soal dan tips dalam menjawab soal yang serupa, sehingga memudahkan siswa dalam mengikuti langkah kerja rumus dalam menyelesaikan soal-soal.
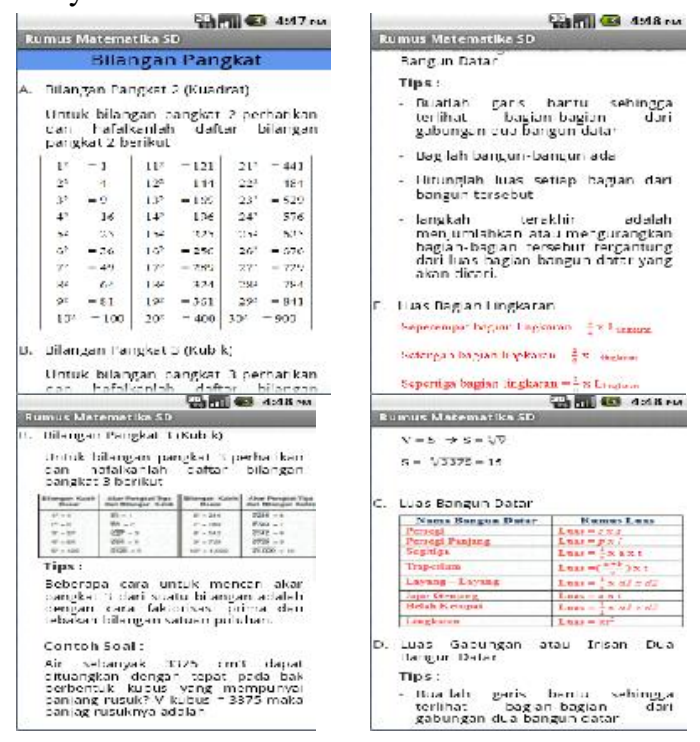

\section{Tampilan Tombol Materi Pengukuran Satuan}

Pada tombol Materi Pengukuran Satuan terdapat rumus Pengukuran Satuan yang memuat urutan langkah kerja, contoh soal dan tips dalam menjawab soal yang serupa, sehingga memudahkan siswa dalam mengikuti langkah kerja rumus dalam menyelesaikan soal-soal.

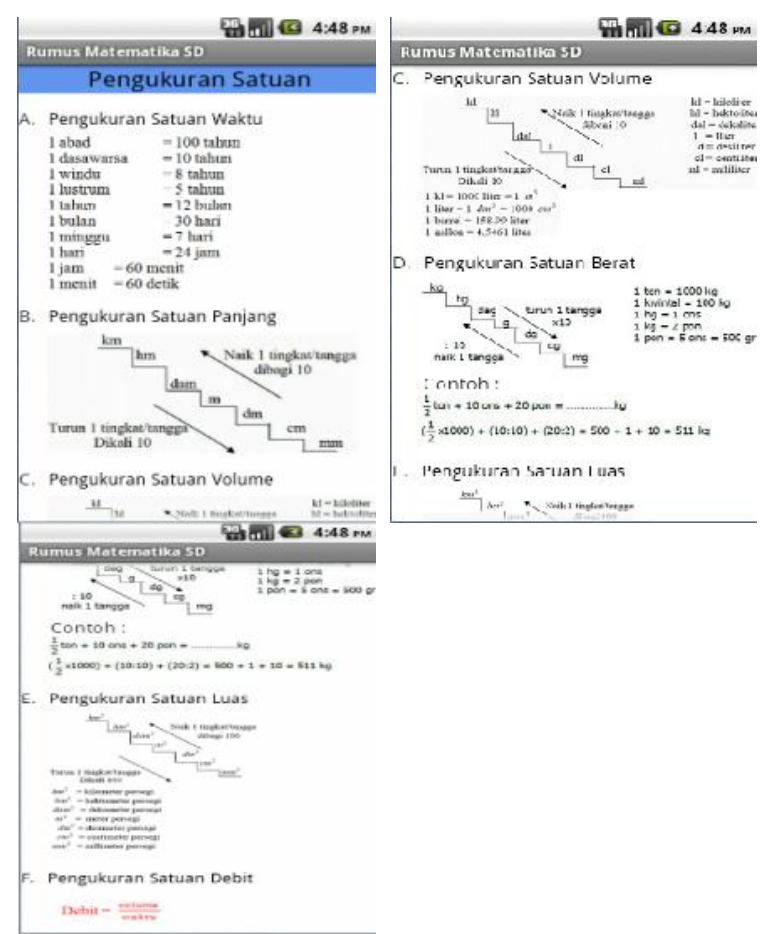

Gambar 8. Tampilan Materi Pengukuran Satuan

\section{Tampilan Tombol Materi Jarak, Waktu dan Kecepatan}

Pada tombol Materi Jarak, waktu dan kecepatan terdapat rumus yang membahas mengenai Jarak, waktu dan kecepatan yang memuat rumus jarak, waktu dan kecepatan tersebut, sehingga memudahkan siswa dalam menyelesaikan soal.

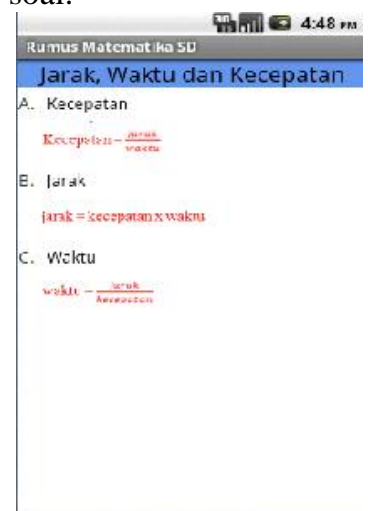

Gambar 9. Tampilan Materi Jarak, Waktu dan Kecepatan

Gambar 7. Tampilan Materi Bilangan Pangkat 
10. Tampilan Tombol Materi Bangun Datar

Pada tombol Materi Bangun Datar terdapat rumus Bangun Datar yang memuat urutan langkah kerja, contoh soal dan tips dalam menjawab soal yang serupa, kemudian juga sifat bangun datar dijelaskan secara rinci dan ringkas sehingga memudahkan siswa dalam mengikuti langkah kerja rumus dalam menyelesaikan soal-soal.
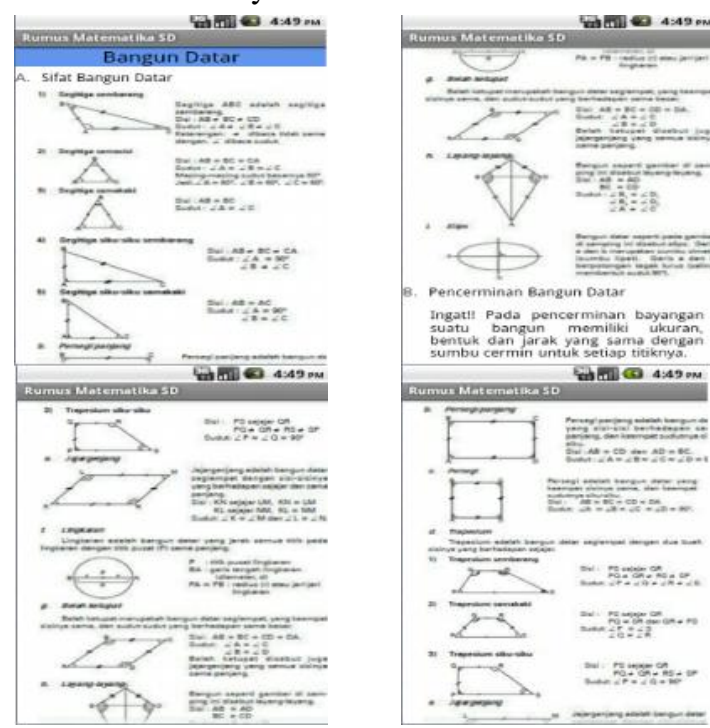

Gambar 10. Tampilan Materi Bangun Datar

\section{Tampilan Tombol Materi Bangun Ruang}

Pada tombol Materi Bangun Ruang terdapat rumus Bangun Ruang yang memuat urutan langkah kerja, contoh soal dan tips dalam menjawab soal yang serupa, kemudian juga unsur-unsur Bangun Ruang dijelaskan secara rinci dan ringkas dalam volume kubus, balok dan prisma segitiga sehingga memudahkan siswa dalam mengikuti langkah kerja rumus dalam menyelesaikan soal-soal.
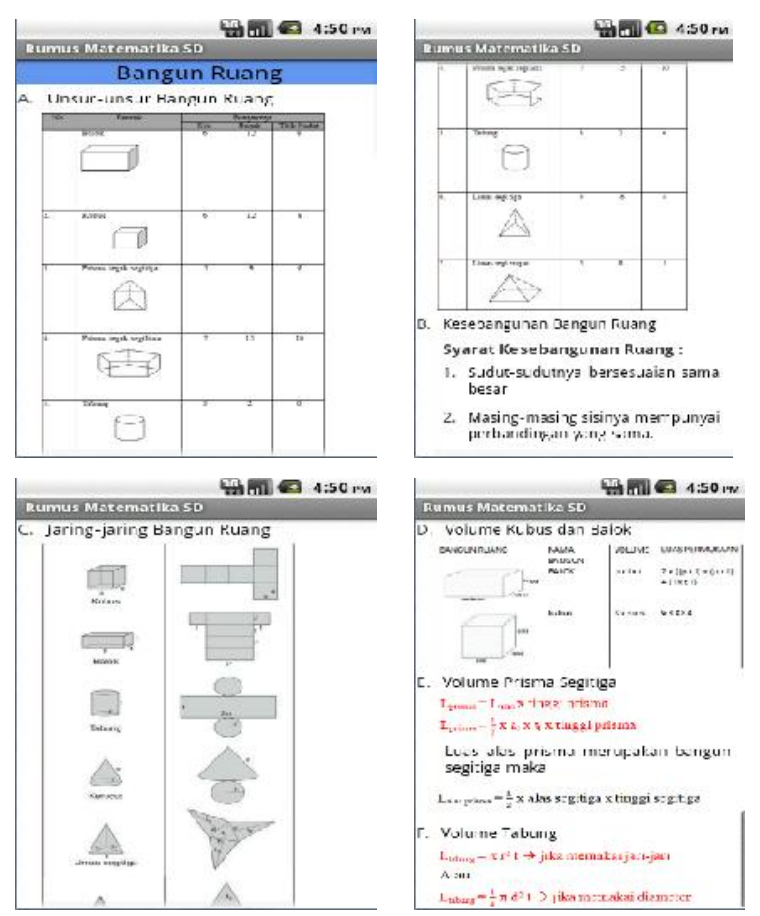

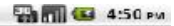

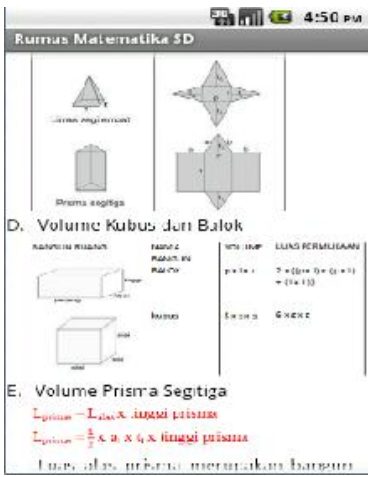

Gambar 11. Tampilan Materi Bangun Ruang

\section{Tampilan Tombol Materi Memahami Kartesius}

Pada tombol Materi Kartesius penjelasan dalam memahami materi kartesius secara ringkas dan rinci.

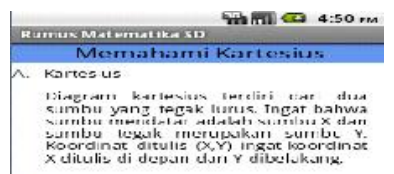

Gambar 12. Tampilan Materi Memahami Kartesius

\section{Tampilan Tombol Materi Diagram}

Pada tombol Materi Diagram penjelasan dalam memahami materi Diagram secara ringkas dan rinci. Sehingga siswa-siswi akan mudah dalam menyelesaikan soal yang disajikan.

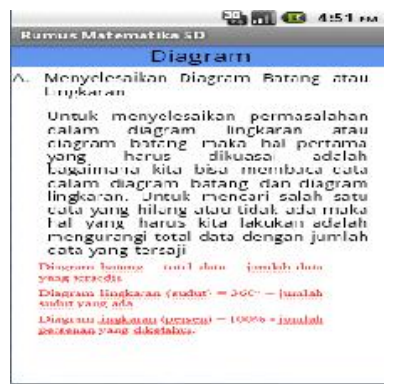

Gambar 13. Tampilan Materi Diagram

\section{Tampilan Tombol Materi Statiska}

Pada tombol Materi Statistika terdapat penjelasan dalam memahami materi Statistika secara ringkas dan rinci. Mulai dari materi rata-rata data tunggal, rata-rata data dalam tabel, rata-rata data dalam diagram batang, modus, median, nilai tinggi dan terendah. Sehingga siswa-siswi akan mudah dalam menyelesaikan soal yang disajikan. 


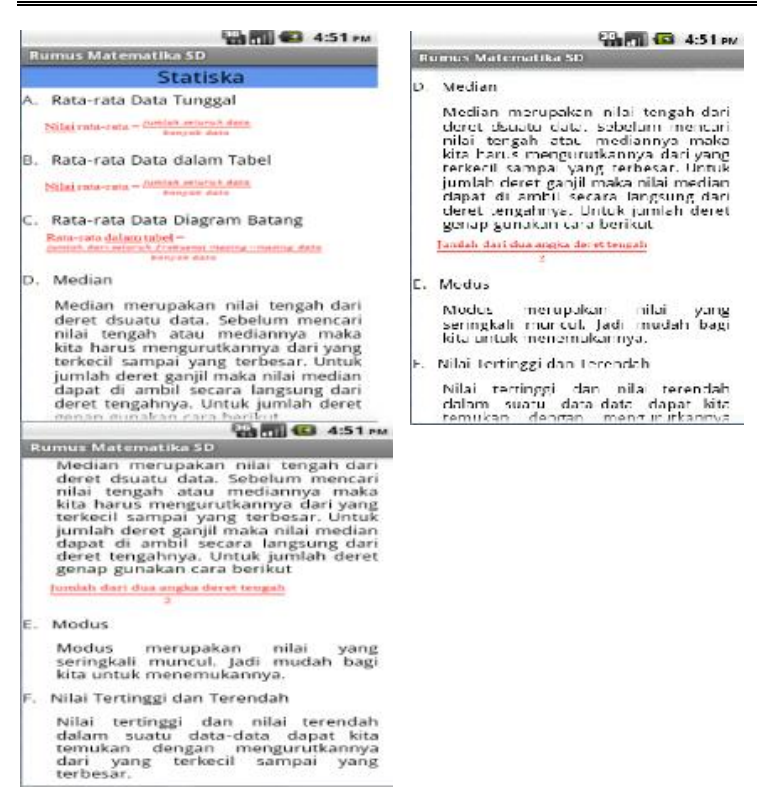

Gambar 14. Tampilan Materi Statiska

\section{Tampilan Tombol Latihan Soal}

Pada aplikasi ini dilengkapi tombol latihan soal yang akan memunculkan soal-soal permateri dari semua materi yang disajikan pada aplikasi berbasis android tersebut.

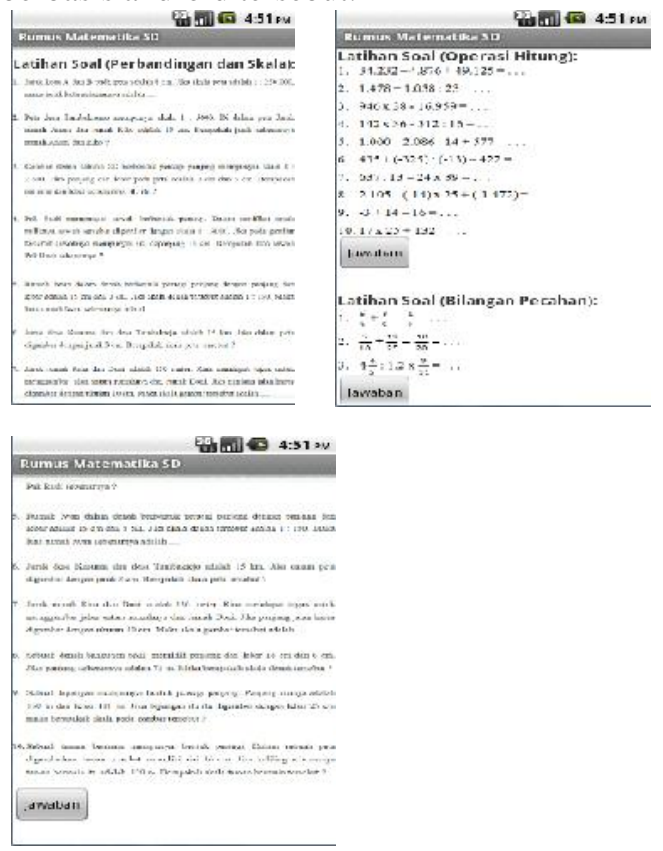

Gambar 15. Tampilan Latihan Soal

\section{Tampilan Tombol Tentang}

Tampilan tombol about (Tentang) ini adalah memuat penjelasan singkat mengenai aplikasi ini menampilkan rumus matematika SD berbasis android.

\section{Rumus Matemative SD \\ Tellatigg
Rainus Matematike so \\ Rumus Matematikă 's, \\ Androir Release November 8,2018 \\ Developer by Januardi Rosyidi .ubis}

Gambar 16. Tampilan Tentang

\section{Tampilan Tombol Bantuan}

Tombol bantuan pada aplikasi ini adalah kontak bantuan untuk siswa dalam membantu siswa dan siswi jika ada yang belum mengerti pada aplikasi ini atau ada terjadi kesalahan saat pengintalan pada handphone siswa-siswi tersebut maka dapat menghubungi kontak person tersebut.

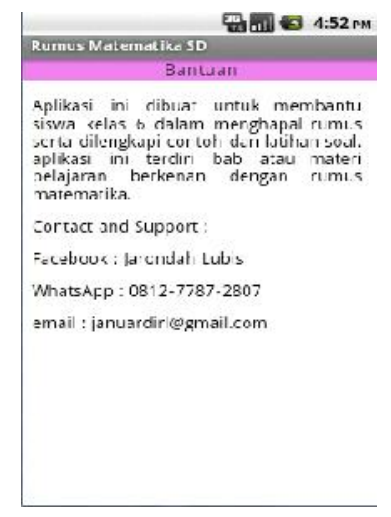

Gambar 17. Tampilan Bantuan

\section{KESIMPULAN}

Berdasarkan hasil pengujian data dan analisa data, perancangan Rumus Matematika Sekolah Dasar Berbasis Android Menggunakan ADT (Android Developer Tools) dapat disimpulkan bahwa :

a. Terdapat materi-materi yang berkenan dengan rumus matematika dan sejalan dengan materi matematika sekolah dasar.

b. Dalam aplikasi tersebut terdapat penjelasan ringkas dan jelas mengenai materi matematika sekolah dasar dalam membantu siswa memahami secara cepat rumus matematika tersebut.

c. Dengan soal latihan maka siswa dapat mengerjakan soal berdasarkan materi tersebut dan dapat menjadi pedoman dasar dalam mengerjakan soal matematika jenis lain yang lebih rumit. 


\section{REFERENSI}

Desmira, Rizal Fauzi.2015. Perancangan Aplikasi

Pembelajaran Rumus Matematika Matriks dan Trigonometri Berbasis Android.

Rochmansyah, AY, 2012. "Pengembangan Aplikasi Pembelajaran Menulis Huruf Arab Mobile Android". Skripsi, Sekolah Tinggi Manajemen Informatika \& Teknik Komputer (STIKOM) Surabaya.

Said, M., 2012. "Aplikasi Pembelajaran RambuRambu Lalu Lintas Berbasis Smart
Phone Android". Tugas Akhir, Universitas Pembangunan Nasional "Veteran".

Latif, MA, 2012. "Perancangan Aplikasi RumusRumus Fisika Berbasis Android".Skripsi, $\quad$ Amikom Yogyakarta.

Putra, FF., Sari, JN., Suhatman, R, 2012, “Aplikasi Pembelajaran Metamorfhosis Berbasis Android Augmented Reality", Jurnal Teknik Informatika, Volume 1, Nomor 1, Politeknik Caltex Riau. 